\title{
Lifestyle of the Employees Working in Hamadan Public Sectors: Application of the Trans-Theoretical Model
}

\author{
Jalal Abdi ${ }^{1} ;$ Hassan Eftekhar $^{1,} ;$ Mahmood Mahmoodi $^{2} ;$ Davod Shojaeizade $^{1} ;$ Roya Sadeghi $^{1}$ \\ ${ }_{1}^{1}$ Department of Health Education and Promotion, School of Public Health, Tehran University of Medical Sciences, Tehran, IR Iran \\ ${ }^{2}$ Department of Epidemiology and Biostatics, School of Public Health, Tehran University of Medical Sciences, Tehran, IR Iran \\ ${ }^{*}$ Corresponding Author: Hassan Eftekhar, Department of Health Education and Promotion, School of Public Health, Tehran University of Medical Sciences, Tehran, IR Iran. Tel: +98- \\ 2188955888, Fax:+98-2188989129, E-mail: eftkhara@sina.tums.ac.ir
}

Received: November 10, 2014; Revised: December 10, 2014; Accepted: December 31, 2014

\begin{abstract}
Background: A healthy lifestyle is a valuable source to reduce the prevalence of health problems, and promoteehealth.
Objectives: The current study aimed to evaluate the lifestyle and obesity status of Hamadan public employees and their status based on the trans-theoretical model (TTM).

Patients and Methods: This analytical cross-sectional study was performed in 2014 on 1200 public employees in Hamadan city, Iran selected through proportional stratified random sampling. Data collection was performed using a three-section questionnaire including demographic characteristics, The FANTASTIC lifestyle questionnaire, and the five-part algorithm. Data were analyzed by SPSS-20 using linear regression, Chi-square, Fisher exact test, and ANOVA.

Results: The mean age of the employees was $38.12 \pm 8.04$ years. Most of the employees (61.7\%) had favorable lifestyle. About half of the employees were at the preparation stage of TTM. Most of the employees were in a poor condition regarding the physical activity and healthy eating habits. In most of the evaluated items, females got higher scores than males. The associations between lifestyle and age, gender, work experience, income satisfaction, and marital status were significant. Moreover, the associations between obesity and work experience, marital status, number of offspring, and gender were significant $(\mathrm{P}<0.05)$. Significant predicting variables of obesity were age and work experience; they explained $31.2 \%$ variance of obesity (adjusted $R^{2}=0.312, R^{2}$ change $=0.01$ ).

Conclusions: Planning health education interventions for employees through effective approaches seems necessary.
\end{abstract}

Keywords:Models, Theoretical; Life Style; Obesity; Physical Activity

\section{Background}

healthy lifestyle is one of the basic health-promotion strategies (1). Based on the health promotion approach, people should be empowered to accept their health responsibility and follow a healthy lifestyle (2). Although evidence supports the importance of lifestyle in promoting health, many people still have unhealthy lifestyles (3). With the global changes of social and economic patterns, sedentary lifestyle is a worldwide phenomen (4). In general, the lifestyle is a collection of attitudes, habits, and desires related to one person or a group (5). Healthy lifestyle is defined as the type of lifestyle that provides, preserves, and enhances the level of health and welfare (6). Noticing the role of lifestyle in preventing diseases, improving the quality of life, increasing life expectancy, and improving mental and physical health is of paramount importance (7). The patterns of lifestyle are deeply rooted in old habits and affect the person's health in the long term (8). More than one third of the deaths occur as a result of unhealthy lifestyles worldwide, which are the main cause of developing cardiovascular diseases, hypertension, type 2 diabetes, tooth decay, stroke, and number of cancers $(9,10)$. Nowadays, lifestyle modification is an important strategy to prevent non communicable diseases (11). The diseases which result from unhealthy lifestyles are the most common causes of mortality and morbidity in Iran as well (12). Usually people spend one third of their time at their workplaces with conditions that may reinforce keeping away from healthy behaviors (13). Maintaining a healthy and productive workforce is essential for employers in public and private sectors (14). The health status is one of the most important reasons of premature retirement and decreased capability of the employees. The health status of the employees may deteriorate due to chronic diseases that originate from certain lifestyles. An unhealthy lifestyle can result in illness, absenteeism, and low productivity of the employees (15). Moreover, healthy employees are more productive, are less likely to be absent from work due to illness, and more involved in their duties (16).

\section{Objectives}

The current study aimed to evaluate the lifestyle and obesity status of the employees working in public orga-

Copyright (C) 2015, Iranian Red Crescent Medical Journal. This is an open-access article distributed under the terms of the Creative Commons Attribution-NonCommercial 4.0 International License (http://creativecommons.org/licenses/by-nc/4.0/) which permits copy and redistribute the material just in noncommercial usages, provided the original work is properly cited. 
nizations of Hamadan, some associated factors, and their position according to trans-theoretical model.

\section{Patients and Methods}

\subsection{Design}

This cross-sectional, descriptive-analytical study was performed on 1200 employees working in the public sectors of Hamadan, west of Iran, in 2014.

\subsection{Participants and Setting}

The research population included the employees of the public organizations. The inclusion criteria were officially employed, male or female above 18 , more than one year of working experience. Individuals with medical condition such as pregnancy, depression or other serious disease were excluded. Twenty two staff were excluded due to pregnancy $(n=8)$, musculoskeletal disorders $(n=6)$ and other serious health problems $(n=8)$.

\subsection{Sampling and Data Collection}

A total of 24551 employees were registered in the governor's office list. According to the results of a prior study in Iran (17) with $80 \%$ power in a two-tailed tests at a significance level of 0.05 , determined the sample size for the study at 1200 . The sampling strategy was based on a proportionate stratified random sampling. The organizations with more than $>50$ employees who had agreed to participate in the study were considered as one stratum. Considering the sample size, proportionate allocation sampling was used to identify a sampling fraction for each organization. The participants were randomly selected from the members' list in each office. Participants were met at workplace for a face to face interview by a trained interviewer. After coordination with the directors of the offices, a questionnaire was distributed among the employees. The researchers provided the necessary information regarding the questionnaire completion and ethical issues including anonymity of the answers. Offices in this study were certain organizational units established according to the law, with legal independence, executed part of the duties, and responsibilities of one of the three executive, legislative, and judicial systems and other legal organizations.

\subsection{Measurement Tools}

Data were collected through a questionnaire with three sections (demographic information, FANTASTIC lifestyle questionnaire, and Marcus's five part algorithm). The FANTASTIC lifestyle questionnaire was developed by Wilson and Ciliska in the Family Medicine Department of McMaster University, Canada. The acronym represents the first letters of the nine domains (in English) in which the 25 questions or items are distributed. Numerous studies have confirmed its reliability and validity $(3,18)$. The ques- tions are designed based on the Likert scale. Questions were coded by points as follows: zero for the first column, 1 for the second,2 for the third,3 for the fourth, and 4 for the fifth column. The total score of FANTASTIC ranges from zero to 100 and higher score indicates a better condition. According to the total score, the respondents were categorized in five categories: excellent (85-100), very good (70-84), good (55-69), regular (35-54), and needing improvement (0-34). The results were interpreted as follows:

“Excellent" indicates that the individual's lifestyle represents an optimal influence for health; "very good" indicates that the lifestyle represents an adequate influence for health; "Good" indicates that the lifestyle represents many benefits for health; "Regular" indicates that the lifestyle represents some benefit for health, although it also poses risks; "Needing improvement" indicates that the individual's lifestyle poses many risk factors. To evaluate the reliability and validity of the questionnaire, it underwent primary translation and re-translation by the author and a number of experts in the field of health education and health promotion. The experts were requested to evaluate the tool in terms of clarity, readability, face validity and relevance. Test-retest was used to evaluate its reliability. The questionnaire was completed by 20 employees twice in a two-week interval and a reliability coefficient of $79 \%$ was obtained. To calculate the body mass index (BMI), weight was measured with a digital scale (Terraillon) without shoes with minimal clothing. A measuring tape was used for height measurement in the standing position without shoes. Each measurement was performed twice and the average was recorded upon difference. The current study employed the trans-theoretical model developed by Prochaska and DiClemente in 1970 to investigate physical activity, as one of the most important items of lifestyle. In this model, people are categorized in five categories regarding the levels and stages of change: a) pre-contemplation: people at this stage do not intend to start the healthy behavior within 6 months; b) contemplation: at this stage, participants are intending to start the healthy behavior within the next six months; c) preparation: people at this stage are determined to change within the next 30 days and have prepared some means; d) action: people at this stage perform the behavior regularly; and e) maintenance: people at this stage perform the behavior for more than six months. The five-part algorithm of Marcus was used to evaluate the stages of change. Its reliability and validity in Iran were confirmed in two studies by Jalilian et al. (19) and Moeini et al. (20).

\subsection{Data Analysis}

Data were analyzed with SPSS-20 using descriptive and analytical statistics. Frequency, percentage, and mean standard deviation were used to describe demographic characteristics. The main statistical tests used in the study were linear regression, Chi square, Fisher exact test, and 
independent t-tests, and analysis of variance (ANOVA). To assess differences in characteristics, chi-square test was used for categorical variables and ANOVA for continuous variables. The relationship between the TTM model and gender was assessed by Fisher exact test. Linear regression was used to assess the association between BMI and variables such as education level, age and work experience.

\subsection{Ethical Considerations}

Ethics committee approval was obtained from the Ethics Committee of Tehran University of Medical Sciences (ID: 9021108006). Informed consent was obtained prior to the study enrollment.

\section{Results}

The mean age of the employees was $38.12 \pm 8.04$ years. Males and females comprised 50.6\% $(n=607)$ and $49.4 \%$ $(n=593)$ of the participants, respectively. The majority of the employees (55.6\%) had bachelor's degrees and 13.2\% had higher degrees. The employees had a mean work experience of $8.52 \pm 14.15$ years. Most of the employees (81.8\%) were married and had 1.24 offspring on average. Table 1 presents the status of the lifestyle of the employees of Iran based on demographic specifications. One of the employees (1\%) had an excellent lifestyle, $21.6 \%$ ( $n$ $=259)$ had very good lifestyles, $61.7 \%(n=740)$ had good lifestyles, $16.1 \%(n=193)$ had regular lifestyles, and the lifestyle required improvement in $0.6 \%(n=7)$ of the em- ployees. There was a significant relationship between the lifestyle and gender, age, work experience, marital status, and income satisfaction $(\mathrm{P}<0.05)$. Table 2 presents different stages of the trans-theoretical model in the item of physical activity based on gender. According to the results, females were in higher stages of change (action and maintenance) in the item of physical activity than males. Regarding smoking (at least one cigarette per day), $86.8 \%$ of the employees did not smoke while $2.8 \%$ $(\mathrm{n}=33)$ smoked more than 10 cigarettes a day. Regarding cola containing drinks (coffee, tea, etc.), 45.8\% $(n=550)$ drank them once or twice a day, 3.2\% $(n=38)$ drank them more than 10 times a day, and 37.1\% $(n=445)$ drank them 3-6 times a day. The other items of FANTASTIC lifestyle questionnaire are summarized in Table 3. In the current study, $71 \%$ of the employees did not have vigorous-intensity physical activity. Only 35.5\% had moderate-intensity physical activity five times or more per week (Table 4). The results of the present study showed a significant relationship between BMI and gender, number of offspring, marital status, and work experience ( $P<0.05)$. BMI increased in the participants with an increase in work experience, the prevalence of overweight and obesity for married participants was higher than single ones, and the BMI increased with an increase in the number of offspring. Multiple linear regression analysis with stepwise method showed that age and work experience were the strongest predictors of obesity; They explained of $31.2 \%$ variance of obesity (adjusted $\mathrm{R}^{2}=0.312, \mathrm{R}^{2}$ change $=0.01$ ).

Table 1. Distribution of Lifestyle Status of the Public Employees Working in Hamadan Public Sector Based on Demographic Characteristics $^{\text {a }}$

\begin{tabular}{|c|c|c|c|c|c|c|}
\hline Demographic Variable & Excellent & Very Good & Good & Regular & Need to Improvement & P-Value \\
\hline Age & & & & & & 0.043 \\
\hline$>35$ & $1(0.1)$ & $85(17.5)$ & $313(64.3)$ & $85(17.5)$ & $3(0.6)$ & \\
\hline$\leq 35$ & - & $174(24.4)$ & $427(59.9)$ & $108(15.5)$ & $4(0.6)$ & \\
\hline Gender & & & & & & 0.022 \\
\hline Male & $1(0.2)$ & $146(24.1)$ & $362(59.6)$ & $94(15.5)$ & $4(0.7)$ & \\
\hline Female & - & $113(19.1)$ & 378963.7) & $99(16.2)$ & $3(0.5)$ & \\
\hline Marriage status & & & & & & 0.002 \\
\hline Married & $1(0.1)$ & $237(24.1)$ & $596(60.7)$ & $142(14.5)$ & $6(0.6)$ & \\
\hline Not Married & - & $21(9.9)$ & $141(66.5)$ & $49(23.1)$ & $1(0.5)$ & \\
\hline Education level & & & & & & 0.174 \\
\hline > Under graduate & - & $90(24)$ & $213(56.8)$ & $69(18.4)$ & $3(0.8)$ & \\
\hline$\leq$ Graduate & $1(0.1)$ & $169(20.5)$ & $527(63.9)$ & $124(15)$ & $4(0.5)$ & \\
\hline Job experience & & & & & & 0.015 \\
\hline$>10$ years & $1(0.2)$ & $92(18.3)$ & $319(63.4)$ & $88(17.5)$ & $3(0.6)$ & \\
\hline 11-20 years & - & $81(21.8)$ & $236(63.4)$ & $55(14.8)$ & - & \\
\hline$>20$ & $1(0.1)$ & $259(21.6)$ & $740(61.7)$ & $193(16.1)$ & $7(0.6)$ & \\
\hline Income satisfaction & & & & & & 0.001 \\
\hline Yes & - & $63(35.4)$ & $98(55.1)$ & $16(9)$ & $1(0.1)$ & \\
\hline No & - & $82(16.6)$ & $295(59.6)$ & $114(23)$ & $4(0.8)$ & \\
\hline Somewhat & $1(0.2)$ & $114(21.6)$ & $347(65.8)$ & $63(12)$ & $2(0.4)$ & \\
\hline
\end{tabular}


Abdi jet al.

\begin{tabular}{|c|c|c|c|}
\hline Stage of change & Male & Female & PValue \\
\hline Pre contemplation & $91(64.1)$ & $51(35.9)$ & \\
\hline contemplation & $92(51.1)$ & $88(48.9)$ & \\
\hline Preparation & $301(51)$ & $289(49)$ & 0.001 \\
\hline Action & $103(44)$ & $131(56)$ & \\
\hline Maintenance & $20(37)$ & $34(63)$ & \\
\hline Total & $607(50.6)$ & $593(49.4)$ & \\
\hline
\end{tabular}

a Data are presented as No. (\%).

Table 3. Distribution of Responding to Fantastic Lifestyle Questionnaire Items ${ }^{a}$

\begin{tabular}{lccccc}
\hline Items & Never & Seldom & Some Times & Often & Always \\
\hline I have someone to talk to & $24(3.5)$ & $117(9.8)$ & $293(24.4)$ & $320(26.7)$ & $428(35.7)$ \\
\hline I give and receive affection & $12(1)$ & $65(5.4)$ & $195(16.3)$ & $523(43.6)$ & $405(33.8)$ \\
\hline I am moderately active & $55(4.6)$ & $132(11)$ & $312(26)$ & $484(40.3)$ & $217(18.1)$ \\
\hline I use drugs & $1158(96.5)$ & $9(0.75)$ & $24(2)$ & $1(0.1)$ & $8(0.65)$ \\
\hline I overuse medications & $574(47.8)$ & $332(27.7)$ & $218(18.2)$ & $49(4.1)$ & $27(2.3)$ \\
\hline I sleep well & $53(4.4)$ & $100(8.3)$ & $257(21.4)$ & $509(42.4)$ & $281(23.4)$ \\
\hline I use seatbelts & $32(2.7)$ & $30(2.5)$ & $90(7.5)$ & $284(23.7)$ & $764(63.7)$ \\
\hline I am able to cope with stress & $29(2.4)$ & $121(10.1)$ & $381(31.8)$ & $526(43.8)$ & $143(11.9)$ \\
\hline I relax and enjoy leisure time & $36(3)$ & $137(11.4)$ & $359(29.9)$ & $478(39.8)$ & $190(15.8)$ \\
\hline practice safe sex & $285(23.8)$ & $37(3.1)$ & $51(4.3)$ & $179(14.9)$ & $648(54)$ \\
\hline I seem to be in a hurry & $213(17.8)$ & $246(20.5)$ & $385(32.1)$ & $263(21.9)$ & $93(7.8)$ \\
\hline I feel angry and hostile & $389(32.4)$ & $362(30.2)$ & $330(27.5)$ & $90(7.5)$ & $29(2.4)$ \\
\hline I am a positive thinker & $32(2.7)$ & $90(7.5)$ & $242(20.2)$ & $548(45.7)$ & $288(24)$ \\
\hline I feel tense and disappointed & $344(28.7)$ & $404(33.7)$ & $341(28.4)$ & $81(6.8)$ & $30(2.5)$ \\
\hline I feel sad and depressed & $382(31.8)$ & $403(33.6)$ & $306(25.5)$ & $27(6)$ & $37(3.1)$ \\
\hline I am satisfied with my job & $61(5.1)$ & $114(9.5)$ & $191(15.9)$ & $491(40.9)$ & $343(28.6)$ \\
\hline I Dar.
\end{tabular}

a Data are presented as No. (\%).

Table 4. Distribution of Physical Activity Status of the Employees Working in Hamadan Public Sectors a

\begin{tabular}{lccccc}
\hline Type of Activity & Less than Once/Week & $\mathbf{1 - 2}$ Twice/Week & 3 Times/Week & 4 Times/Week & 5 or More Times/Week \\
\hline $\begin{array}{l}\text { Moderate- Intensity } \\
\text { (walking, housework...) }\end{array}$ & $825(71)$ & $162(13.5)$ & $92(7.7)$ & $32(2.7)$ & $62(5.2)$ \\
$\begin{array}{l}\text { Vigorous-Intensity (run- } \\
\text { ning, cycling...) }\end{array}$ & $282(23.5)$ & $211(17.6)$ & $170(14.2)$ & $11(9.3)$ & $426(35.5)$ \\
\hline
\end{tabular}

${ }^{\mathrm{a}}$ Data are presented as No. (\%).

Table 5. BMI Distribution of the Employees Working in Hamadan Public Sectors

\begin{tabular}{lcc}
\hline Status & BMI & No. $(\%)$ \\
\hline Weight Deficiency & $<18.5$ & $12(1)$ \\
\hline Normal & $18.6-24.99$ & $482(40)$ \\
Overweight & $25-29.99$ & $539(44.9)$ \\
\hline Obesity class I & $30-34.99$ & $143(11.9)$ \\
\hline Obesity class II & $35-39.99$ & $18(1.5)$ \\
\hline Obesity class III & $>40$ & $6(0.5)$ \\
\hline
\end{tabular}

\section{Discussion}

A healthy lifestyle is a valuable source of decreasing the prevalence and effect of health problems, promoting health, coping with stressors, and improving the quality of life $(6,21-23)$. Considering the effective role of employees as valuable human resources in delivering services, the current study was conducted to evaluate the lifestyle of the employees working in the public sectors of Hamadan and some associated factors using the trans-theoretical model. In the current study, the lifestyle of the majority of the employees was good. The sta- 
tus of females employees was better than males ones in almost all items. Moreover, 58\% of the employees were overweight or obese. Determination of the status of the individuals in terms of the stages of health related behaviors is an appropriate reflection of their attitude and performance; the results can provide basic information to design appropriate educational programs for the designated behavior and thus help to prevent the related diseases and enhance health and well-being in the society (24-27). Physical activity is one of the most important items of the lifestyle. It has a very important role in the prevention of lifestyle related diseases and health promotion, and enhances psychological performance, increases friendly gatherings, improves night's sleep, and is considered an appropriate recreation (6). Recent studies have shown that a small percentage of adults are engaged in the recommended levels of physical activity (28). In the current study, about half of the participants were at the preparation stage, which was compatible with the results of the study by Mazlomi (29). In a study by Haakstad et al. (30), 45.6\% of the participants were at the pre-action stage. Moeini et al. also reported similar findings (20). about $70 \%$ of the employees did not have vigorous-physical activity and their moderate-physical activity was not favorable either. In a study by Fayaz-bakhsh et al. (31), 44.1\% of the participants did not exercise at all. The results of a study by Pirzadeh showed that $76 \%$ of the participants had moderately favorable physical activity (32). Limitations in time and place are the most important factors for the lack of physical activity and weight management in employees $(33,34)$. Health is perceived differently by the young and the elderly (35). The current study found a significant relationship between the lifestyle and age, which was in line with the results of the study by Pirzadeh (32). Gender has a strong independent effect on the health and disease status, and selection of lifestyles and living habits (36). Studies have shown that females use more healthcare services comparing males, but underreport their health status when compared to males (37). The currentstudy found a significant relationship between gender and lifestyle and Females had a better status in all items comparing males. Based on Trans-Theoretical Model females were at higher stage of change (action and maintenance) than males. Education and lifetime learning are important determinants of the lifestyle (38). No significant relationship was found between the education and lifestyle, maybe due to the similarity of the educational level in the majority of the employees. This finding was compatible with the results of the study by Pirzadeh et al. (32) but different from the findings of other studies $(39,40)$. Income and income satisfaction result in differences in the socioeconomic status of the people in a society. A higher income results in relative well-being and satisfaction which can affect the lifestyle. There is a confirmed relationship between income and mortality in the litera- ture (41). A significant relationship was found between income satisfaction and lifestyle. The family and its composition are key determinants of lifestyle behaviors and married people have a higher quality of life. A significant relationship was also observed between marital status and lifestyle. One of the consequences of unhealthy lifestyle is weight gain and obesity, which is regarded as the biggest public health problem worldwide by the World Health Organization (WHO) (42). The relationship between the BMI and lifestyle was significant in the current study, since the increase in BMI was more in those who followed unhealthier lifestyles. This finding was in line with the results of the studies by Pirzadeh in Isfahan, Iran (32) and van Wier in the Netherlands (33). Work environment is one of the determinants of health, and employees spend a lot of their time at work. Employees with more years of work experience tend to adopt a more sedentary lifestyle. In the current study, the BMI increased with an increase in the years of work experience. BMI was higher in married versus single employees. It seems that marriage causes some changes in the lifestyle, especially in nutrition and physical activity, which may result in weight gain and obesity. Social support is a protective factor for mental health in adults and especially the elderly (43). Health promotion behaviors are observed more frequently in individuals who have strong and positive social support networks (36). Moreover, social support and interpersonal relations are among the most stable health indicators in different studies (12). The current study noted that the employees received favorable social support and the employees had a healthier status in terms of smoking, since $86.8 \%$ of them did not smoke. This finding was similar to the results of the studies by Pirzadeh (32). In a study by Fayaz-bakhsh et al. (31), 79.5\% of the participants had never smoked a cigarette. About $18.1 \%$ of the participants in the current study stated that they always had a balanced diet. In the study conducted by Pirzadeh, $18 \%$ of the participants had a moderately favorable nutritional status (32). Since the status of many items including physical activity and healthy diet of the employees is not favorable, and considering the results of the current study, it is important to plan health education interventions for the employees, focusing on the effective approaches based on behavior change theories like the trans-theoretical model in terms of time and place.

\subsection{Limitations and Strong Points}

Regarding the limitations, the current study was performed among the employees of the public sectors and the employees working in the private sectors were not included; moreover, the status of the employees only in one of the items of the lifestyle (physical activity) was assessed which could affect the generalizability of the results. Its large sample size and theory-based nature were 
however its strong points.

\section{Acknowledgements}

This paper was part of Ph.D. thesis of the first author in health education and health promotion at Tehran University of Medical Sciences (registration code: 9021108006). The authors wish to thank all employees and directors of public offices, institutions, and organizations of Hamadan who participated in this study.

\section{Authors' Contributions}

Study concept and design: Abdi, Eftekhar, Shojaeizade and Sadeghi; Analysis and interpretation of data: Mahmoodi, Abdi and Eftehkhar; Study supervision: Eftekhr; Critical revision of the manuscript: Eftekhar, Sadeghi

\section{References}

1. Enjezab B, Farajzadegan Z, Taleghani F, Aflatoonian A. Internal motivations and barriers effective on the healthy lifestyle of middle-aged women: A qualitative approach. Iran J Nurs Midwifery Res. 2012;17(5):390-8.

2. Spratt J, Shucksmith J, Philip K, Watson C. 'Part of who we are as a school should include responsibility for well-being': links between the school environment, mental health and behaviour. Pastor Care Educ. 2006;24(3):14-21.

3. Rodriguez Anez CR, Reis RS, Petroski EL. Brazilian version of a lifestyle questionnaire: translation and validation for young adults. Arq Bras Cardiol. 2008;91(2):92-8.

4. Lee PH, Macfarlane DJ, Lam TH, Stewart SM. Validity of the International Physical Activity Questionnaire Short Form (IPAQ-SF): a systematic review. Int J Behav Nutr Phys Act. 2011;8:115.

5. Longman P. Longman dictionary of contemporary English. 4th edNew York: Longman; 2008.

6. Hekmatpou D, Shamsi M, Zamani M. The effect of a healthy lifestyle program on the elderly's health in Arak. Indian J Med Sci. 2013;67(3-4):70-7.

7. Lai KL, Tzeng RJ, Wang BL, Lee HS, Amidon RL, Kao S. Health-related quality of life and health utility for the institutional elderly in Taiwan. Qual Life Res. 2005;14(4):1169-80.

8. Kilani H, Al-Hazzaa H, Waly MI, Musaiger A. Lifestyle Habits: Diet, physical activity and sleep duration among Omani adolescents. Sultan Qaboos Univ Med J. 2013;13(4):510-9.

9. World Health Organization.. The world health report 2002 - Reducing Risks, Promoting Healthy Life. WHO: Geneva; 2002.

10. World Health Organization.. Diet, Physical activity and Health 55th World Health assembly. Geneva: WHO; 2002.

11. Suraj S, Singh A. Study of sense of coherence health promoting behavior in north Indian students. Indian J Med Res. 2011; 134(5):645-52.

12. Tol A, Tavassoli E, Sharifirad GR, Shojaezadeh D. [The Relation between Health-Promoting Lifestyle and Quality of Life in Undergraduate Students at School of Health, Isfahan University of Medical Sciences, Iran]. J Health Sys Res. 2011;7(4):442-8.

13. Hjarnoe L, Leppin A. Health promotion in the Danish maritime setting: challenges and possibilities for changing lifestyle behavior and health among seafarers. BMC Public Health. 2013;13:1165.

14. Perez AP, Phillips MM, Cornell CE, Mays G, Adams B. Promoting dietary change among state health employees in Arkansas through a worksite wellness program: the Healthy Employee Lifestyle Program (HELP). Prev Chronic Dis. 2009;6(4)

15. Rongen A, Robroek SJ, van Lenthe FJ, Burdorf A. Workplace health promotion: a meta-analysis of effectiveness. Am J Prev Med. 2013;44(4):406-15.

16. StrijkJE, Proper KI, van Mechelen W, van der Beek AJ. Effectiveness of a worksite lifestyle intervention on vitality, work engagement, productivity, and sick leave: results of a randomized controlled trial. Scand J Work Environ Health. 2013;39(1):66-75.

17. Mohamadi N, Shobeiri F, Kheirollahi A, Omidi A, Amini R. [ the prevalance of obesity and overwight in women who reffered to hamadan health care centers]. J Hamadan Nurs Medwifery Fac. 2011.

18. Ramirez-Velez R, Agredo RA. [The Fantastic instrument's validity and reliability for measuring Colombian adults' life-style]. Rev Salud Publica (Bogota). 2012;14(2):226-37.

19. Jalilian M, Darabi M, Sharifirad G, Kakaei H. [Interventional Program based on Trans- Theoretical Model to Promote Regular Physical Activity in Office Workers].J Health Sys Res. 2013;9(2):188-95.

20. Moeini B, Jalilian M, Hazavehei SMM, Moghimbeigi A. [Promoting Physical Activity in Type 2 Diabetic Patients: A Theory-Based Intervention]. J Health Sys Res. 2012;8(5):824-32.

21. Sengupta P, Krajewska-Kulak E. Is Mind-Body Relaxation By Yoga is Effective to Combat with Lifestyle Stress? Ann Med Health Sci Res. 2013;3(Suppl 1):S61-2.

22. McCalla JR, Juarez CL, Williams LE, Brown J, Chipungu K, Saab PG Promoting healthy lifestyle behaviors: the Heart Smart Discussion Activity. J Sch Health. 2012;82(12):572-6.

23. Tovar A, Chui K, Hyatt RR, Kuder J, Kraak VI, Choumenkovitch SF et al. Healthy-lifestyle behaviors associated with overweight and obesity in US rural children. BMC Pediatr. 2012;12:102.

24. Jones C, Jancey J, Howat P, Dhaliwal S, Burns S, McManus A, et al. Utility of stages of change construct in the planning of physical activity interventions among playgroup mothers. BMC Res Notes. 2013;6:300.

25. Paxton RJ, Nigg CR, Motl RW, McGee K, McCurdy D, Matthai CH et al. Are constructs of the transtheoretical model for physical activity measured equivalently between sexes, age groups, and ethnicities? Ann Behav Med. 2008;35(3):308-18.

26. Nigg CR, Geller KS, Motl RW, Horwath CC, Wertin KK, Dishman RK. A Research Agenda to Examine the Efficacy and Relevance of the Transtheoretical Model for Physical Activity Behavior. Psychol Sport Exerc. 2011;12(1):7-12

27. Skaal L, Pengpid S. The predictive validity and effects of using the transtheoretical model to increase the physical activity of healthcare workers in a public hospital in South Africa. Trans Behav Med. 2012;2(4):384-91.

28. Malik SH, Blake H, Suggs LS. A systematic review of workplace health promotion interventions for increasing physical activity. BrJ Health Psychol. 2014;19(1):149-80.

29. Mazlomi S, Mohamadi M. [Evaluation of The Trans-Theoretical Model in diet of Pre Diabetic patients in Yazd]. Iran J Diabetes Lipid. 2012;12(2):167-72.

30. Haakstad LA, Voldner N, Bo K. Stages of change model for participation in physical activity during pregnancy. J Pregnancy. 2013;2013:193170.

31. Fayaz-Bakhsh A, Khajeh-kazemi R, Soleymani Nejad M, Rahimi F Jahangiri L, Shams M. [The InternetUsing and Health: Students' Knowledge, Attitude and Lifestyle Related to the Internet]. Hakim Res J. 2011;14(2):96-105.

32. Pirzadeh A, Sharifirad GR. [A survey of healthy life style in teachers in 4 district in Esfahan]. J Health Sys Res. 2011;7(6):1075-81.

33. van Wier MF, Ariens GA, Dekkers JC, Hendriksen IJ, Pronk NP, Smid T, et al. ALIFE@Work: a randomised controlled trial of a distance counselling lifestyle programme for weight control among an overweight working population [ISRCTN04265725]. BMC Public Health. 2006;6:140.

34. Lees FD, Clarkr PG, Nigg CR, Newman P. Barriers to exercise behavior among older adults: a focus-group study. J Aging Phys Act. 2005;13(1):23-33.

35. Wolff $\mathrm{JK}$, Brose A, Lovden $\mathrm{M}$, Tesch-Romer $\mathrm{C}$, Lindenberger U, Schmiedek F. Health is health is health? Age differences in intraindividual variability and in within-person versus between-person factor structures of self-reported health complaints. Psychol Aging. 2012;27(4):881-91.

36. Baheiraei A, Mirghafourvand M. Health Promotion From Concepts to Practice.Iran: noor-e-Danesh publication; 2011.

37. Bertakis KD, Azari R, Helms LJ, Callahan EJ, Robbins JA. Gender differences in the utilization of health care services. J Fam Pract. 2000;49(2):147-52. 
38. Rafieifar SH. Technical Reports Collection On Health Education. 1nd edIRAN-Qazvin: Alhadi Pulication; 2004.

39. Beser A, Bahar Z, Buyukkaya D. Health promoting behaviors and factors related to lifestyle among Turkish workers and occupational health nurses' responsibilities in their health promoting activities. Ind Health. 2007;45(1):151-9.

40. Hui WH. The health-promoting lifestyles of undergraduate nurses in Hong Kong. J Prof Nurs. 2002;18(2):101-11.

41. Larrimore J. Does a higher income have positive health ef- fects? Using the earned income tax credit to explore the income-health gradient. Milbank Q. 2011;89(4):694-727.

42. Dodd JM, Turnbull D, McPhee AJ, Deussen AR, Grivell RM, Yelland LN, et al. Antenatal lifestyle advice for women who are overweight or obese: LIMIT randomised trial. $\mathrm{Br}$ Med J. $2014 ; 348$.

43. Li H, Ji Y, Chen T. The roles of different sources of social support on emotional well-being among Chinese elderly. PLoS One. 2014;9(3). 